\title{
O ensino de literatura no curso de Pedagogia: uma presença necessária
}

\section{The teaching of literature in the Pedagogy Course: a necessary presence}

\author{
Diana Maria Leite Lopes Saldanha* \\ Marly Amarilha**
}

\begin{abstract}
RESUMO
Este artigo traz um mapeamento do ensino de literatura nos cursos de pedagogia de 27 universidades federais do país. Toma-se como pressuposto que a literatura é fundamental para a formação humana e, portanto, deve fazer parte do currículo dos futuros professores da educação infantil e dos anos iniciais do ensino fundamental, responsáveis pela introdução das crianças na cultura letrada. A análise indica que a presença, no caso específico, da literatura infantil, na formação dos pedagogos é ainda incipiente e vulnerável aos meandros da estrutura curricular. É imprescindível introduzir a literatura como forma de propiciar ao docente, em formação inicial formal, uma vivência teórica e prática sobre seu ensino, cujo intuito seja de contribuir para a sua atuação como futuro mediador de leitura.
\end{abstract}

Palavras-chave: Ensino. Literatura Infantil. Pedagogia. Formação Inicial Formal. Currículo.

\begin{abstract}
This article brings a literature teaching mapping in pedagogy courses at 27 federal universities of this country (Brazil). It is assumed that literature is fundamental for human educational formation and therefore, must be part of the curriculum of future yearly childhood education as well as of elementary school initial levels teachers, who are responsible for the introduction of children to the literate culture. Analysis indicates that the presence, in the

* Universidade do Estado do Rio Grande do Norte. Pau dos Ferros. Rio Grande do Norte. Brasil. E-mail: dianalsaldanha@yahoo.com.br . https://orcid.org/0000-0002-5239-0317.

** Universidade Federal do Rio Grande do Norte. Natal. Rio Grande do Norte. Brasil. E-mail: marlyamarilha@yahoo.com.br. https://orcid.org/0000-0002-0467-6919.
\end{abstract}


specific case of children's literature in the qualification of educators, is still insufficient and vulnerable to the inside curricular structure. It is crucial to introduce literature as a means to proportionate to the teacher in their initial formal education a theoretical and practical experience about teaching with the intention of contributing to their action as a future literature mediator.

Keywords: Teaching.Children's Literature. Pedagogy. Initial Formal Education. Curriculum.

\section{Introdução}

A leitura, a formação do leitor, o ensino de literatura infantil e juvenil permanecem relevantes tópicos de pesquisas e discussões no Brasil contemporâneo. Enquanto premiações nacionais e internacionais (Prêmio Hans Christian Andersen; Prêmio Jabuti; Prêmio Ibero-americano SM de Literatura Infantil e Juvenil) reconhecem a qualidade da produção literária para crianças e jovens de autores brasileiros e estudos mostram o desenvolvimento significativo dessas produções (LUFT, 2010; COELHO, 1991), o desempenho dos leitores é repetidamente criticado. Esses debates têm ratificado que ainda perduram sérios problemas relacionados ao domínio da leitura nos diferentes níveis de escolarização de nossas crianças e jovens, fato comprovado pelas sucessivas avaliações como Programa Internacional de Avaliação de Estudantes - Pisa - (2016); o Índice de Desenvolvimento da Educação Básica -Ideb - (2016), a despeito de críticas que possam ser feitas a essas avaliações. Um aspecto que especialistas apontam como influente nesse desempenho insatisfatório em leitura é a precária formação que os professores recebem para atuarem na área; incluímos, nesse caso, a formação em literatura.

Essa problemática evidencia-se também em nossa experiência docente no ensino superior, especificamente no curso de Pedagogia, quando acompanhamos os relatos dos alunos que fazem estágios nas escolas e constatam a pouca presença da literatura infantil no cotidiano de sala da aula, dos primeiros anos de escolarização. Em muitos casos, a literatura infantil é abordada de forma irregular e assistemática, preenchendo de maneira improvisada um vazio pedagógico, sem a preocupação com a formação do leitor (AMARILHA, 2012). Do mesmo modo, percebemos que o ensino superior também apresenta lacunas com relação à formação do leitor de literatura, fato que compromete toda a rede de leitura, tendo em vista que é responsabilidade do curso de Pedagogia formar os futuros professores de crianças, jovens e adultos dos primeiros níveis de ensino. 
A ausência do ensino de literatura na formação inicial formal (aqui entendida como aquela oferecida pela universidade) do pedagogo e, consequentemente, a necessidade de uma formação que incentive e aprecie a leitura como um valor e uma habilidade necessária evidenciam que há um espaço formativo pouco reconhecido no currículo do curso. A precária cultura literária com que muitos graduandos de Pedagogia chegam à universidade também pode ser fator da precariedade que pode afetar o futuro desempenho profissional. Os relatos de muitos desses graduandos, nas aulas de literatura, deixam clara a pouca vivência que tiveram com práticas de leitura ao longo da educação básica, prevalecendo as experiências com a leitura eminentemente protocolar, para preenchimento de fichas ou para realizar avaliações.

Nesse cenário, propomos discutir a problemática da ausência da literatura infantil no contexto da formação inicial formal de professores que atuarão na educação infantil e anos iniciais do ensino fundamental. Podemos pensar, por homologia, que as lacunas deixadas na formação de professores produzirão lacunas também na sua atuação em sala de aula.Por isso, é preciso refletir inicialmente sobre o ensino que temos na universidade, especificamente no curso de Pedagogia.

\section{Algumas pistas nos conduziram a seguir a trilha escolhida}

Este estudo sobre o ensino de literatura infantil na formação inicial formal do pedagogo surge como uma necessidade emergente com vistas a uma educação transformadora, pautada nos ideais de uma formação humana e cidadã. Entendemos que literatura é uma criação linguística que representa um testemunho da capacidade inventiva do ser humano, por meio da qual transcende sua natureza primária. Assim sendo, sua presença na formação do professor é indispensável, sobretudo para aquele que medeia o rito iniciático à cultura letrada.

A pouca presença da literatura na escola, muitas vezes, explica-se pela dificuldade na implantação de políticas públicas na área, pela ausência de bibliotecas escolares e por se entender que literatura é território exclusivo do curso de Letras.

Estudo realizado por Silva S. F. (2015), sobre as políticas de leitura no Brasil (documentos, programas e diretrizes), indica a existência de investimento e incentivo à leitura, entretanto os dados dos níveis de leitura dos brasileiros demonstrados nas últimas pesquisas sugerem que essas políticas não estão apresentando resultados satisfatórios, parecendo não atingir a eficácia desejada. 
Partindo dessas reflexões, começamos a nos indagar: a ausência de formação dos primeiros professores - os pedagogos - não terá parcela de responsabilidade nesse quadro pouco promissor? A leitura de literatura pode não ser interditada de forma explícita, mas as possibilidades de sua realização permanecem interrompidas direta ou indiretamente pelos 11,5 milhões de analfabetos existentes (IBGE, 2017), pela educação de má qualidade, pela ausência de bibliotecas e pela falta de políticas públicas consolidadas que, efetivamente, viabilizem e garantam a democratização da leitura. Pode-se ainda acrescentar o fato que, mesmo sendo considerada essencial para a formação do cidadão, a leitura de textos literários ainda é uma atividade secundária na sociedade, como demonstra a série histórica da pesquisa Retratos da Leitura no Brasil (GALENO, 2001; GALENO, 2008; FAILLA, 2012; FAILLA, 2016). As políticas de leitura, a exemplo do Programa Nacional Biblioteca na Escola - PNBE - (definitivamente encerrado em 2017), esbarram em uma corrente que se interrompe antes que alcance os objetivos pelos quais se criaram, como bem demonstra trabalho já citado de Silva S. F. (2015).

Sobre a ineficiência dessas políticas, Berenblum (2009), no documento Por uma Política de Formação de Leitores, argumenta que a formação do professor é condição básica para que se efetive uma política de formação de leitores no âmbito da escola. Nessa lógica, defendemos que essa proposta não sirva somente para a formação continuada, mas, sobretudo, deve ser efetivada na formação inicial formal do pedagogo, que está sendo preparado para atuar nas escolas. Esse quadro de referências gerou o interesse em conhecer alguns meandros do ensino de literatura oferecido no curso de Pedagogia.

Conforme argumentamos, a literatura é área fundamental na formação do licenciado em Pedagogia. Entretanto, devido ao vínculo tradicional da área com o curso de Letras, costuma-se pensar que a ele pertença, com exclusividade e em definitivo. Esse argumento, do nosso ponto de vista, não procede porque a licenciatura em Letras prepara o professor para atuar do $6 .^{\circ}$ ao $9 .^{\circ}$ ano do ensino fundamental e no ensino médio. Então, pergunta-se: a educação infantil, os anos iniciais do ensino fundamental e a EJA ficam sem a literatura?

Não se trata de desalojar a literatura do curso de Letras, mas de referendar sua presença no curso de Pedagogia para atender às demandas fundamentais e específicas dessa licenciatura, que forma professores da educação infantil, dos anos iniciais do ensino fundamental e da Educação de Jovens e Adultos. Destaca-se ainda que a literatura oferecida a esses níveis de ensino atendidos pela Pedagogia, excetuando-se a EJA, é a literatura infantil escassamente lida, estudada ou oferecida nos cursos de Letras.Esse quadro revela que a ausência da literatura na formação do pedagogo fragiliza seu agir profissional e essa si- 
tuação precisa ser avaliada sob a perspectiva de um currículo que, efetivamente, oportunize o acesso a saberes fundamentais à sua atuação.

A natureza lúdica, ficcional e comunicativa do texto literário atrai o neoleitor para a leitura. Ao atraí-lo, justifica, consolida e amplia a habilidade de ler. Assim, a literatura mostra as possibilidades que a escrita e a leitura oferecem. Nessa lógica, é de fundamental importância que a literatura esteja presente no curso de Pedagogia para favorecer a entrada das novas gerações na cultura letrada. Acrescente-se que a leitura de literatura propicia adentrar no universo humano, conhecer suas características, peculiaridades, seus anseios, amores e dissabores, o que favorece o alargamento de horizontes, pouco possível em outras formas de criação. Diante dessa premissa, é razoável perguntar: a literatura não deveria integrar a grade curricular obrigatória do curso de Pedagogia?

\section{Literatura: território interdisciplinar, transdisciplinar}

As discussões sobre currículo proporcionaram um entendimento de como os saberes são sistematizados nas instituições de ensino. O currículo não é neutro, mas território de disputas, no qual o grupo vencedor determina os conhecimentos necessários à formação a ser oferecida em determinado curso. Tratam-se de saberes que, geralmente, são selecionados para atender objetivos da sociedade de cada época. Como resultado, as aspirações humanísticas, muitas vezes, são submetidas a uma visão técnica, fragmentada. Esse vínculo com o pragmatismo estabeleceu no sistema educacional e universitário um paradigma curricular por disciplinas que se consolidou e, até hoje, resiste a mudar.

Sobre essa problemática, Santos (2013) aponta a necessidade de um saber contextual, de um diálogo entre as diferentes áreas de conhecimento para integrar os currículos nas universidades. Morin (2003) esclarece que o retalhamento das disciplinas impede a aprendizagem do global e, por isso, defende um ensino interdisciplinar que envolva todas as áreas de conhecimento. Acrescentamos que um conhecimento global, contextualizado, que dialogue com todas as áreas de conhecimento e possibilite ao sujeito o conhecimento complexo planetário da condição humana, ultrapassa os limites das disciplinas, da interdisciplinaridade para a transdisciplinaridade, pois

[...] a Transdisciplinaridade é uma teoria do conhecimento, é uma compreensão de processos, é um diálogo entre as diferentes áreas do saber 
e uma aventura do espírito. A Transdisciplinaridade é uma nova atitude, é a assimilação de uma cultura, é uma arte, no sentido da capacidade de articular a multirreferencialidade e a multidimensionalidade do ser humano e do mundo. Ela implica numa postura sensível, intelectual e transcendental perante si mesmo e perante o mundo. Implica, também, em aprendermos a decodificar as informações provenientes dos diferentes níveis que compõem o ser humano e como eles repercutem uns nos outros (MELLO; BARROS; SOMMERMAN, 2002, p. 9-10).

É importante destacar que a transdisciplinaridade estabelece um novo paradigma na compreensão sobre a relação dos seres humanos com o conhecimento e sobre sua própria experiência de estar no mundo. Reconhece a complexidade do seu destino e a incompletude como marca de sua condição.

Nesse sentido, retomamos as discussões sobre a importância da literatura para o ensino global, contextualizado e humano que se pretende introduzir, pois a literatura é transdisciplinar. Além de encantar e propiciar a experiência estética, o texto literário é um manancial de saberes que atravessa os territórios dos saberes disciplinares. Entendemos que uma obra literária reúne uma diversidade de conhecimentos que possibilitam apreender várias disciplinas, a condição humana, as subjetividades, os problemas e os conflitos existentes na vida. Seguindo essa lógica, podemos afirmar que a literatura é saber indispensável, inigualável e insubstituível para a formação do sujeito e, por essa razão, deve estar presente nos currículos universitários e escolares porque promove a abertura de perspectivas, favorece a uma abordagem transdisciplinar dos saberes convergindo para a própria experiência de vida, que desconhece fronteiras, visto que,

[...] a visão transdisciplinar é resolutamente aberta na medida que ultrapassa o campo das ciências exatas devido ao seu diálogo e sua reconciliação, não apenas com as ciências humanas, mas também com a arte, a literatura, a poesia e a experiência espiritual (Carta da Transdisciplinaridade, Artigo 5, 1994).

A literatura em seu tecido multidimensional da experiência humana explora novos conhecimentos, instigando a leitura plural, sob diferentes ângulos, da realidade e do ser humano.

O ensino de literatura como conhecimento transdisciplinar também ganha notoriedade nas ideias de Coelho (2000, p. 24), que concebe a literatura como um "autêntico e complexo exercício de vida, que se realiza com e na 
Linguagem - esta complexa forma pela qual o pensar se exterioriza e entra em comunicação com os outros pensares". Espaço de convergência do mundo exterior e do mundo interior, a Literaturavem sendo apontada como uma das disciplinas mais adequadas para interligar diversos saberes. Coelho (2000) vê a probabilidade de a literatura ser o fio de Ariadne no labirinto do ensino, o eixo organizador de unidades de estudo, ao propor uma metodologia com viés transversal, interdisciplinar, transdisciplinar.

\section{Saberes necessários à formação do pedagogo: há lugar para a literatura?}

Os egressos do curso de Pedagogia atuarão com crianças, jovens e adultos, especialmente como professores das primeiras letras, que contribuirão no processo de desenvolvimento de leitura e da escrita. Partindo do princípio de que a literatura abarca uma diversidade de saberes, sendo uma criação cultural que contribui para a formação do leitor, desenvolve a imaginação, aciona a fantasia e conduz o leitor a refletir sobre seu cotidiano e absorver novas experiências, passamos a analisar a sua inserção nos cursos de Pedagogia, começando pelas diretrizes e pelos documentos norteadores desse curso.

T. T. da Silva (2001) enfatiza que a política curricular, metamorfoseada em currículo, executa um processo de inserção de alguns saberes e de alguns indivíduos, excluindo outros. Por meio do currículo, são efetivados os ideais de grupos sociais e políticos da sociedade. O currículo torna-se o eixo central dos sistemas educacionais, à medida que abarca uma carga de desejos, particularidades, reconhecimento, espaços conquistados e diversidade de saberes. Nas palavras de Arroyo (2013, p. 13), o currículo é um território em disputa, ou seja, "[...] é o território mais cercado, mais normatizado. Mas também o mais politizado, inovado, ressignificado". Nesse sentido, ao pensarmos na diversidade de currículos, deparamo-nos com diretrizes e demais documentos que os normatizam e organizam, os quais devem compor os conhecimentos que serão transmitidos nas instituições educacionais.

Focalizamos inicialmente as Diretrizes Curriculares de Pedagogia, DCNs/2006, observando os componentes curriculares para essa licenciatura, com o intuito de averiguarmos se existe inclusão do ensino de literatura na formação dos futuros professores da educação básica. No artigo 2. ${ }^{\circ}$, especificamente no segundo parágrafo, inciso II, as diretrizes apresentam as contribuições do curso de Pedagogia para a educação por meio de estudos teórico-práticos, investigação e reflexão crítica: 
$\S 2^{\circ} \mathrm{O}$ curso de Pedagogia, por meio de estudos teórico-práticos, investigação e reflexão crítica, propiciará:

I - o planejamento, execução e avaliação de atividades educativas;

II - a aplicação ao campo da educação, de contribuições, entre outras, de conhecimentos como o filosófico, o histórico, o antropológico, o ambiental-ecológico, o psicológico, o linguístico, o sociológico, o político, o econômico, o cultural (BRASIL, 2006, p. 1).

Dentre os conhecimentos propostos para o campo da educação, destacamos o linguístico e o cultural, pela intrínseca relação com o texto literário. A literatura, devido à sua natureza de linguagem verbal, possibilita uma interação com a língua individual e coletiva, promovendo o acesso aos conhecimentos linguísticos, em sua dimensão inventiva. Do mesmo modo, funda-se na cultura de uma sociedade e propicia dela partilhar. Assim, o leitor no contato com a literatura insere-se em uma experiência intelectual, social, estética e afetiva que tem sua linguagem e sua cultura. Ao interagir com o texto literário, ele passa a alcançar novos aprendizados, interpretá-los, ressignificá-los e construir novos conhecimentos. A literatura é um bem cultural, isto é, é a manifestação dos pensamentos e acontecimentos imaginários, apresentados de maneira polifônica e, por essa razão, transmite a multiplicidade de saberes e de experiências ao leitor, fazendo-o se acercar de problemas e discussões que permearam épocas distintas e ainda oferece especulações sobre o futuro.

As Diretrizes Curriculares Nacionais - DCNs - (2006) propõem, no seu artigo $3 .^{\circ}$, um repertório de informações e habilidades formado por uma pluralidade de conhecimentos teóricos e práticos com que o graduando de Pedagogia deverá trabalhar:

Art. $3^{\circ} \mathrm{O}$ estudante de Pedagogia trabalhará com um repertório de informações e habilidades composto por pluralidade de conhecimentos teóricos e práticos, cuja consolidação será proporcionada no exercício da profissão, fundamentando-se em princípios de interdisciplinaridade, contextualização, democratização, pertinência e relevância social, ética e sensibilidade afetiva e estética (BRASIL, 2006, p. 1, grifos nossos).

Os princípios que fundamentam os conhecimentos teóricos e práticos a serem consolidados no exercício da profissão de pedagogo abrangem uma diversidade de saberes, que nos remetem à necessidade da inserção da literatura como criação artística que possibilitará a consolidação desses saberes em sala de aula. 
Ao assinalarmos os princípios da interdisciplinaridade, contextualização, democratização e pertinência nas diretrizes, observamos que o texto literário contempla esses aspectos, pois expande as fronteiras do conhecido, do vivido, e propicia a articulação de novas experiências, conforme já enfatizado por Zilberman (2008), quando defende que o consumo do texto literário leva a práticas socializadoras que, ao serem incentivadas, apresentam-se democráticas. A sensibilidade afetiva e estética é intrínseca à literatura, à linguagem e à ficção, posto que os vazios deixados no texto levam o leitor de literatura a desenvolver a imaginação, a fantasia, a sentir emoção, a se identificar com as personagens e a vivenciar histórias de outros que se entrelaçam com a sua. Para Silva E. T. (2008), é difícil expor a vivência com a literatura porque sua essência é sentida, vivida. "O amálgama da experimentação da linguagem literária: difícil de descrever, mas fácil de sentir quando concretamente vivido pelo leitor.” (SILVA, E. T., 2008, p. 25). Essa experiência proporciona expandir as possibilidades de vida, enfrentando problemas e desafios rotineiros com novas perspectivas e construindo conhecimentos.

No tocante à interdisciplinaridade, conforme discutimos anteriormente, percebemos a literatura como arsenal de saberes que ultrapassa os conhecimentos previstos nas diferentes áreas de conhecimentos. A literatura como prática complexa de linguagem configura-se como uma das probabilidades mais vantajosas no planejamento e na organização do ensino em perspectiva interdisciplinar e transdisciplinar, abrindo espaço para a articulação dos saberes por meio das disciplinas e construindo novos. O saber literário, como aponta Barthes (2007), nunca é inteiro nem derradeiro, ou seja, não está completo, nem fechado, mas abre um leque de possibilidades, sendo flexível e passível de alterações.

Com relação à estrutura do curso de Pedagogia, proposta no artigo $6 .^{\circ}$ das diretrizes, o conhecimento dever ser multidimensional, respeitando a diversidade nacional e a autonomia das instituições. O que nos chamou atenção foram as alíneas (d) e (e) do primeiro parágrafo desse mesmo artigo, que estabelecem:

d) utilização de conhecimento multidimensional sobre o ser humano, em situações de aprendizagem;

e) aplicação, em práticas educativas, de conhecimentos de processos de desenvolvimento de crianças, adolescentes, jovens e adultos, nas dimensões física, cognitiva, afetiva, estética, cultural, lúdica, artística, ética e biossocial (BRASIL, 2006, p. 3).

A estrutura indicada está em consonância com os princípios que fundamentam os conhecimentos teóricos e práticos, ratificando a importância do saber 
literário para compor a organização curricular do curso de Pedagogia. A literatura envolve o conhecimento multidimensional sobre o ser humano, pois trata de questões, peculiaridades e características tipicamente humanas e desenvolve de forma inigualável as dimensões cognitiva, afetiva, estética, cultural, lúdica, artística, ética e biossocial.

Percebemos que as DCNs/2006 não apresentam nitidamente termos como literatura, ensino de literatura, literatura infantil e saberes literários para integrar os conhecimentos teóricos e práticos do curso de Pedagogia em sua estrutura curricular. Contudo os fundamentos que norteiam essa formação demonstram claramente a pertinência de a literatura compor o currículo do curso, dadas as diversidades de saberes que ela articula e sua função humanizadora no desenvolvimento do ser humano, consequentemente do professor.

Considerando a importância das orientações legais para a organização e estrutura dos currículos, especificamente do curso de Pedagogia, analisamos os Referenciais Curriculares Nacionais dos Cursos de Bacharelado e Licenciatura (2010). Ressaltamos que o perfil do egresso licenciado em Pedagogia está em consonância com o exposto pelas DCNs (2006) e os temas abordados na formação lançam a literatura infantojuvenil como conhecimento que irá compor essa formação, como podemos evidenciar:

\section{TEMAS ABORDADOS NA FORMAÇÃO}

História, Filosofia e Sociologia da Educação; Fundamentos da Infância; Didática; Pesquisa e Prática Pedagógica; Alfabetização e Letramento; Conteúdos e Métodos: da Educação Infantil, da Educação de Jovens e Adultos, do Ensino da Língua Portuguesa, da Matemática, da História, da Geografia, das Ciências, das Artes e da Educação Física; Psicologia da Educação; Psicopedagogia; Educação Comparada; Educação Não Formal; Legislação Educacional; Organização do Trabalho Docente; Teoria e Prática de Currículo; Políticas Educacionais; Gestão Educacional e Escolar; Planejamento Educacional e de Ensino; Avaliação Educacional e de Ensino; Literatura Infantojuvenil; Tecnologias da Informação e Comunicação aplicadas à Educação; Educação Inclusiva; Probabilidade e Estatística; Língua Brasileira de Sinais (LIBRAS); Pluralidade Cultural e Orientação Sexual; Ética e Meio Ambiente; Relações Ciência, Tecnologia e Sociedade (CTS) (BRASIL, 2010, p. 88, grifo nosso).

Após a análise desses documentos, partimos para a realização de um mapeamento sobre a oferta do ensino de literatura nos cursos de Pedagogia de 27 universidades federais do país, representando cada estado da federação, pois 
consideramos relevante que a licenciatura em Pedagogia deva oferecer literatura, porque são esses professores que irão atuar na educação infantil e nos primeiros anos do ensino fundamental, portanto serão os responsáveis pelos ritos iniciativos das novas gerações no acesso à linguagem como patrimônio cultural, imaginário e humano, conforme vimos enfatizando. Sendo assim, fizemos, então, um levantamento preliminar das disciplinas ofertadas na graduação em Pedagogia. Os resultados mostram que das 27, 11 delas, ou seja, apenas em $41 \%$ das instituições, 0 curso de Pedagogia oferece como obrigatória uma disciplina na área de literatura. As nomenclaturas variam: Literatura Infantil, Literatura Infantojuvenil, Infância e Literatura, Teoria e Prática de Literatura e outras terminologias afins. Porém é significativo o número de universidades que oferecem disciplinas na área como optativas, são 14 instituições, que representam 52\% do total, mesmo assim com variação bastante irregular na carga horária, de $30 \mathrm{~h}$ a $60 \mathrm{~h}$ semanal. Esse quadro é relevante porque indica uma tendência de crescimento da presença da literatura em Pedagogia, ou pelo menos insinua certa sensibilidade à área. Por outro lado, como já enunciado anteriormente, currículo é um território de disputas, então, podemos concluir que esses indicadores assinalam que a oferta de Literatura no curso de Pedagogia não é consenso, pois ainda não conquistou total legitimidade como disciplina obrigatória. É na condição de obrigatoriedade que uma área se estabelece institucionalmente e, para que isso aconteça, a literatura ainda tem um largo espaço a ser ocupado, no caso específico do currículo de Pedagogia.

A presença insuficiente do ensino de literatura dos currículos de Pedagogia e, consequentemente, a falta de preparação teórico-metodológica dos futuros professores acentuam o quadro incipiente do ensino de literatura nas escolas exposto por Silva E. T. (2008), no qual não ocorre a fruição, o prazer e a liberdade decorrente do encontro do leitor com a literatura. O professor que não dispuser de uma formação que proporcione conhecer a riqueza do texto literário e a experiência estética dificilmente terá condições de explorar a sensibilidade e a diversidade de conhecimentos presentes na literatura, conforme explica o autor:

A literatura pode ser tudo (ou pelo menos muito) ou pode ser nada, dependendo da forma como for colocada e trabalhada em sala de aula. Tudo, se conseguir unir sensibilidade e conhecimento. Nada, se todas as suas promessas forem frustradas por pedagogias desencontradas (SILVA, E. T., 2008, p. 46).

A lacuna deixada na formação inicial formal do docente poderá implicar prática insatisfatória na sala de aula. A didatização inadequada do texto literário 
é uma delas, pois sua utilização como pretexto para o ensino de gramática ou a interpretação mecânica "do que o autor quer dizer", tarefas meramente pragmáticas, retiram da literatura sua essência de criação artística que propicia ao leitor a transição entre o mundo real e a ficção, que propicia a fantasia, a imaginação, o diálogo, o alargamento de compreensão dos conflitos, problemas, crises, encontros e desencontros da vida. Sem contar o uso do texto literário como pretexto para ensino moralizante, limitando-o a discurso monológico, sem explorar suas possibilidades polissêmicas e emancipatórias. Esses caminhos costumam ser utilizados por professores sem formação adequada em literatura e seu ensino.

A oferta de disciplina relacionada à literatura no curso de Pedagogia ganha maior clareza quando investigamos o número de graduandos que terão esse acesso. Assim, para termos uma visão mais acurada sobre a formação dos graduandos, especificamente se esses terão oportunidade de cursar uma disciplina na área de literatura, julgamos relevante saber quantas vagas são oferecidas por ano pelos cursos de Pedagogia das universidades corpus deste estudo. Nosso intuito é de averiguar quantos alunos, aproximadamente, terão a oportunidade de cursar a disciplina Literatura (ou não) durante a formação inicial formal, conforme dados abaixo (Gráfico 1):

\section{GRÁFICO 1- DEMONSTRATIVO DO NÚMERO DE ALUNOS QUE CURSAM PE- DAGOGIANAS IES E A RELAÇÃO COM ENSINO DE LITERATURA NA FORMAÇÃO INICIAL FORMAL}

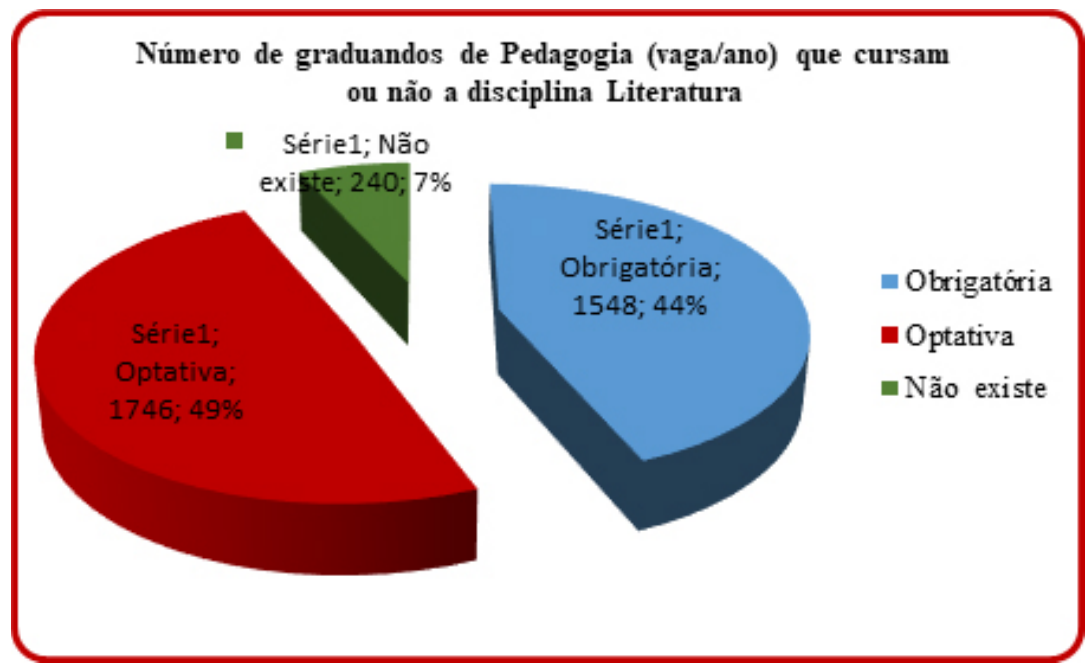

FONTE: SALDANHA, 2016. Dados elaborados pela pesquisadora conforme documentos da pesquisa. 
Conforme observamos, das 27 instituições, há uma média de 3.534 alunos que ingressam no curso de Pedagogia por ano. Desses ingressantes, há em média 1.548 discentes que terão, obrigatoriamente, a oportunidade de cursar a disciplina Literatura no percurso de sua formação. Outros 1.746 estão em universidades que oferecem a disciplina em caráter optativo, dependendo de uma série de circunstâncias para serem ofertadas ou não. Lamentavelmente, contabilizam-se 240 alunos que, certamente, não cursarão a disciplina, porque esta não consta no programa de ensino dos cursos.

Segundo Faria (2010), a exclusão da literatura, especificamente da literatura infantojuvenil dos currículos da formação de professores, é decorrente do fato de esta não ser considerada como verdadeira, ou seja, o estudo e a produção da literatura para crianças e jovens sofrem certo preconceito, já que essa produção ficcional é, muitas vezes, vista como "não literária". De fato, sabemos que o preconceito com a minoridade do destinatário repercute em toda produção cultural destinada à infância. Essa premissa também foi apresentada, anteriormente, por Peter Hunt (2010, p. 27), ao apontar:

[...] para muitos acadêmicos, a literatura infantil [...] não é assunto. Seu próprio tema parece desqualificá-la diante da consideração adulta. Afinal, ela é simples, efêmera, acessível e destinada a um público definido como inexperiente e imaturo. Não é, como certa vez um professor universitário me disse, 'um assunto adequado ao estudo acadêmico'.

Sob essa ótica, a literatura para crianças é vista com descaso, desinteresse, contrapondo-se à ideia da literatura como criação artística indispensável à criança para o desenvolvimento do gosto pela leitura, instigando reações diversas de caráter cognitivo, afetivo, emocional e estético. Hunt (2010) acrescenta que esse fato se agrava devido à validação de textos limitadores e à didatização, que controla e reduz as possibilidades de interpretação e interação com o texto. A propósito, o autor afirma:

A aceitação ampla de textos limitadores não só restringe o pensamento dos leitores como também a capacidade de pensar. A desconsideração desse problema faz parte de uma desconsideração geral da literatura infantil por sociolinguísticas e psicolinguísticas, e reflete a enorme influência que os mediadores menos preparados exercem na produção da literatura infantil. A maioria dos leitores pode se sentir superior ao material escri- 
to para crianças e, por isso, eles se sentem mais livres para prescrever (HUNT, 2010, p. 173).

A discussão trazida pelo autor reincide na necessidade da formação teórica e, acrescentamos, crítica e metodológica, para os professores que irão atuar em sala de aula. Ao trabalhar com livros de literatura, nesse caso, direcionados para crianças, o docente precisa se desprender do pedantismo, em muitos, decorrente do desconhecimento e capacitar-se para entender que a literatura infantil é uma produção que busca trazer a voz da criança frente ao mundo que a recebe. De maneira que é preciso conhecer esse repertório para que o trabalho de aproximação com os jovens leitores se realize de maneira efetiva. Para tanto, o professor necessita de formação sólida que contribua para sua preparação como mediador do texto literário para crianças, jovens ou adultos, reconhecendo a polissemia da literatura para qualquer idade e em qualquer época.

\section{Algumas conclusões}

Os estudos realizados ratificam que a literatura é imprescindível porque articula conhecimento interdisciplinar, transdisciplinar, interligando e atravessando diversas disciplinas, saberes de diferentes áreas que integram os currículos escolares e acadêmicos. Nesse percurso, o texto literário, como construção que atravessa fronteiras, toca a alma humana, mostrando situações relacionadas ao comportamento, aos desejos, aos sonhos, aos conflitos vivenciados pelo ser humano, e modifica o nosso olhar sobre o individual, o cultural e o social. Sob essa ótica, reconhecemos que a literatura é essencial para a formação do sujeito, razão pela qual entendemos que ela precisa ter espaço no currículo do curso de formação de professores.

Com esse entendimento e convicção, julgamos que ela deva integrar a formação inicial formal dos pedagogos, que são os responsáveis por receber e apresentar às crianças, aos jovens e adultos da EJA os sabores/saberes da literatura, incentivar e fomentar o gosto por sua leitura e mediá-la com vistas à sua formação como leitor e como ser humano.

Evidenciamos, neste estudo, que a literatura começa a estar presente nos cursos de licenciatura em Pedagogia das universidades pesquisadas e que existe um movimento acadêmico para a inserção desse saber, contudo sua presença institucional ainda é incipiente, vulnerável. Constatamos que a ausência da li- 
teratura na formação inicial formal do pedagogo deixa uma lacuna que precisa ser preenchida. Entendemos que toda mudança proposta, nesse caso ao curso de licenciatura em Pedagogia, não implica somente modificações nos projetos pedagógicos e em suas estruturas curriculares, mas também mudanças de valores, ruptura com paradigmas preestabelecidos para dar lugar à chegada de novos axiomas. Essa ruptura não se dá de forma aleatória, nem desinteressada, pois enfrenta os enquadramentos do currículo como instância institucional, acadêmica de poder, nem sempre fundamentada em necessidades formativas. Fazer face a esses enquadramentos significa adentrar em um território de tensões, de constantes disputas, de poder, de interesses diversos. Nessa lógica, entendemos que essas mudanças se relacionam a um novo projeto de vida, de humanidade que desejamos para nós e para as novas gerações.

\section{REFERÊNCIAS}

AMARILHA, Marly (Org.). Educação e leitura. Natal: EDUFRN, 1999.

AMARILHA, Marly. Estão mortas as fadas? Literatura infantil e prática pedagógica. 9. ed. Petrópolis: Vozes, 2012.

ARROYO, Miguel G. Currículo, território em disputa. 5. ed. Petrópolis: Vozes, 2013.

BARTHES, Roland. Aula. 12. ed. Tradução de Leyla Perrone-Moisés. São Paulo: Cultrix, 2007.

BERENBLUM, Andréa. Por uma formação de leitores. Brasília: Ministério da Educação, Secretaria de Educação Básica, 2009.

BRASIL. Resolução CNE/CP n. 1, de 15 de maio de 2006. Conselho Nacional de educação/Curso de Pedagogia. Brasília, 2006. Disponível em: <http://portal.mec.gov.br/cne/ arquivos/pdf/rcp01_06.pdf $>$. Acesso em: 02 set. 2014.

BRASIL. Referenciais Curriculares Nacionais dos Cursos de Bacharelado e Licenciatura. Brasília, 2010. Disponível em: <http://www.castelobranco.br/site/arquivos/pdf/ Referenciais-Curriculares-Nacionais-v-2010-04-29.pdf>. Acesso em: 15 mar. 2016.

BRASIL. Programa Internacional de Avaliação de Estudantes (PISA). Relatório Nacional PISA 2015. Brasília, DF: Inep, 2016. Disponível em: <http://portal.mec.gov.br/ component/content/article?id=42761 . . Acesso em: jan. 2017.

COELHO, Nelly Novaes. Literatura: arte, conhecimento e vida. São Paulo: Peirópolis, 2000. 
COELHO, Nelly Novaes. Panorama Histórico da Literatura Infantil/Juvenil. São Paulo: Ática, 1991.

FAILLA, Zoara (Org.). Retratos da Leitura no Brasil 3. São Paulo: Imprensa Oficial do Estado de São Paulo: Instituto Pró-Livro, 2012.

FAILLA, Zoara (Org.). Retratos da leitura no Brasil 4. Rio de Janeiro: Sextante, 2016. Disponível em: <http://prolivro.org.br/home/images/2016/RetratosDaLeitura2016_LIVRO_EM_PDF_FINAL_COM_CAPA.pdf >.Acesso em: 20 set. 2017.

FARIA, Maria Alice. Como usar a literatura infantil na sala de aula. 5. ed. 1. reimp. São Paulo: Contexto, 2010.

FERREIRA, Hugo Monteiro. A literatura na sala de aula: uma alternativa de ensino transdisciplinar. 2008. 377 f. Tese (Doutorado em Educação) - Universidade Federal do Rio Grande do Norte, Natal, 2008.

GALENO, Amorim (Coord.). Retratos da Leitura no Brasil 1. São Paulo: Imprensa Oficial/Instituto Pró-Livro, 2001. Disponível em: <http://www.abrale.com.br/wp-content/ uploads/retratos-leitura-no-brasil.pdf $>$. Acesso em: 20 set. 2017.

GALENO, Amorim (Org.). Retratos da Leitura no Brasil 2. São Paulo: Imprensa Oficial/ Instituto Pró-Livro, 2008. Disponível em: <http://prolivro.org.br/images/antigo/1815. pdf.Acesso em: 20 set. 2017.

HANS CHRISTIAN ANDERSEN AWARDS. Disponível em: <http://www.ibby.org/ awards-activities/awards/hans-christian-andersen-awards/?L=0>. Acesso em: 20 jan. 2018.

HUNT, Peter. Crítica, teoria e literatura infantil. Tradução de Cid Knipel. São Paulo: Cosac Naify, 2010.

INEP - Instituto Nacional de Estudos e Pesquisas Educacionais Anísio Teixeira. Índice de Desenvolvimento da Educação Básica. Disponível em: < http://portal.inep.gov.br/artigo/-/ asset_publisher/B4AQV9zFY7Bv/content/dados-do-ideb-2015-ja-estao-disponiveis-para-consulta/21206>. Acesso em: 13 set. 2017.

INSTITUTO BRASILEIRO DE GEOGRAFIA E ESTATÍSTICA. Agência de notícias. Disponível em: <https://agenciadenoticias.ibge.gov.br/agencia-noticias/2012-agencia-de-noticias/noticias/21255-analfabetismo-cai-em-2017-mas-segue-acima-da-meta-para-2015.html>. Acesso em: 20 jan. 2018.

LUFT, Gabriela. A literatura juvenil brasileira no início do século XXI: autores, obras e tendências. Estudos de Literatura Brasileira Contemporânea, n. 36. Brasília, julho-dezembro de 2010, p. 111-130. Disponível em: <http://periodicos.unb.br/index.php/ estudos/article/view/2884/2491>. Acesso em: 23 jul. 2017.

MELLO, Maria F.; BARROS, Vitória Mendonça; SOMMERMAN, Américo. Educação e Transdisciplinaridade II. São Paulo: TRIOM, 2002.

MORIN, Edgar. A cabeça bem-feita: repensar a reforma, reformar o pensamento. Tradução de Eloá Jacobina. 8. ed. Rio de Janeiro: Bertrand Brasil, 2003. 
PRÊMIO JABUTI. Disponível em: <https://www.premiojabuti.com.br>. Acesso em: 31 de jan. 2018.

PRÊMIO IBERO-AMERICANO SM DE LITERATURA INFANTIL E JUVENIL. Disponível em: <http://fundacaosmbrasil.org/iniciativa/premio-ibero-americano-sm-de-literatura-infantil-e-juvenil/>. Acesso em: 20 de jan. 2018.

PRIMEIRO CONGRESSO MUNDIAL DA TRANSDISCIPLINARIDADE, Carta da Transdisciplinaridade. Portugal, Convento de Arrábida, 1994. Disponível em: $<$ http:// unesdoc.unesco.org/images/0012/001275/127511por.pdf>. Acesso em: 02 mar. 2016.

PROGRAMA NACIONAL BIBLIOTECA DA ESCOLA (PNBE). Disponível em: $<$ http://portal.mec.gov.br/programa-nacional-biblioteca-da-escola $>$. Acesso em: 19 set. 2017.

SANTOS, Boaventura de Sousa. Pela mão de Alice: o social e o político na pós-modernidade. 14. ed. São Paulo: Cortez, 2013.

SILVA, Ezequiel Theodoro da. Literatura e Pedagogia: reflexão com relances de depoimento. In: ZILBERMAN, Regina; SILVA, Ezequiel Theodoro. Literatura e pedagogia: ponto e contraponto. São Paulo: Global; Campinas: ALB - Associação da Leitura do Brasil, 2008.

SILVA, Sayonara Fernandes. O Programa Nacional Biblioteca da Escola - PNBE: da gestão ao leitor na educação infantil de Natal. 2015. 284 f. Dissertação (Mestrado em Educação) - Programa de Pós-Graduação em Educação, Centro de Educação, Universidade Federal do Rio Grande do Norte, Natal, 2015.

SILVA, Tomaz Tadeu da. O currículo como fetiche: a poética e a política do texto curricular. 2. ed. Belo Horizonte: Autêntica, 2001.

ZILBERMAN, Regina; SILVA, Ezequiel Theodoro. Literatura e pedagogia: ponto e contraponto. São Paulo: Global; Campinas: ALB - Associação da Leitura do Brasil, 2008.

Texto recebido em 08 de junho de 2018. Texto aprovado em 08 de agosto de 2018. 